\title{
Caciquismo y Poder Empresarial El papel político de las compañias mineras en la provincia de Huelva (1898-1923)
}

\section{MARIA ANTONIA PEÑA GUERRERO}

\section{INTRODUCCION}

Quizás evocando a su compatriota Gerald Brenan, David Avery -el antiguo archivero de la Compañía de Río Tinto- buscó para uno de los capítulos sobre su Historia de las Minas de Río Tinto el bien expresivo título de :El laberinto. A lo largo de las apenas treinta páginas que escribió bajo estas dos palabras, Avery nos dejó con pinceladas no siempre demasiado firmes y, generalmente, tendenciosas la sugerencia explícita de que la Compañía no había sido sólo uno de los poderes económicos más importantes de la España del siglo XIX y XX -rla mayor fuente privada de puestos de trabajo.y uno de los recursos tributarios más sustanciosos del Estado- sino también un verdadero poder político: con sorprendentes ramificaciones que iban desde lo local a lo nacional ${ }^{1}$.

El deseo de profundizar en esta sugerencia nos ha llevado a devanar el hilo de las relaciones entre el poder político y el poder económico en la provincia de Huelva y a encontrarnos, en el marco de un sistema caciquil apuntalado por el Partido Conservador, con el comportamiento político de las compañías mineras ${ }^{2}$.

Aun conscientes de que la utilización recíproca de ambos poderes no es una característica privativa de una época o de un espacio concretos, hemos delimitado un período preciso que nos permita abordar con stf.cientes elementos de juicio las relaciones entre el empresariado mineı y los modos funcionales del sistema caciquil: la Restauración y,

(1; AVERY,D.: Nunca en el cumpleaños de la Reina Victoria. Historia de las minas de Rio Tinto. Labor, Barcelona, 1985, pp. 277 y s.

(2) También han mencionado el papel político de la Compañía de Río Tinto CALERO AMOR, A. M.: Movimientos sociales en Andalucia (1820-1936). Siglo XXI, Madrid, 1976 y GIL VARON, L.: -Las' luchas obreras en Río Tinto (1888-1939). en RODRIGUEZ AGUILERA, R., y otros: Seis estudios sobre el proletariado andaluz (1868-1939). Ayuntamiento de Córdoba, 1984, pp. 129-173. 
en concreto, su segunda etapa (1898-1923), por lo de crítico y transitorio que en ella se reconoce. Del origen de estas ingerencias políticas de las sociedades mineras y de la perduración que les intuimos en etapas políticas posteriores deben dar cuenta otros trabajos de investigación cuya exhaustividad excede las posibilidades de estas páginas.

\section{LOS MOVILES DE LA INTERVENCION POLITICA}

En opinión de Avery, la intervención de la Río Tinto Company Limited en la política fue un posicionamiento fundamentalmente defensivo, una cuestión de supervivencia derivada de su carácter de compañía extranjera cercada por la xenofobia, obligada a defender sus amenazados intereses económicos y envuelta en un sistema político caciquil al que tenía que combatir para no ser fagocitada. Verdaderamente, se trata ésta de una justificación hasta cierto punto comprensible, con un irrecusable fondo de verdad, que, sin embargo, no debe hacernos perder la verdadera dimensión de los hechos. Bien vale que en su fuero interno el Consejo de la Compañía sólo buscase mantener el nivel -a ser posible aceleradamente creciente- de sus dividendos y que, para ello, no dudase en disponer cuantas defensas fuesen necesarias. En realidad lo que percibimos es que, para combatir la xenofobia, la Compañía se convirtió en xenófoba; para mantener su poderío económico se transformó en un gestor político y para contrarrestar la ofensiva de los caciques terratenientes se transmutó en el más poderoso y "caciquil. de todos ellos. A todas luces, estamos ante un característico fenómeno de utilización del poder político por parte de un poder económico.

La improvisación del comportamiento político insinuada por Avery se nos antoja premeditación si tenemos en cuenta que las ingerencias políticas no fueron una costumbre exclusiva de la Compañía de Río 'Tinto -cuya magnitud, incluso, podría justificar-, sino una pauta normal de funcionamiento en gran parte de las compañías mineras del Andévalo onubense, de pequeña o mediana entidad, con unos móviles concretos susceptibles de ser globalizados.

De alguna forma, el análisis de cualquiera de los objetivos perseguidos por las compañías mineras -en especial la de Río Tinto- en sus relaciones con la política nos llevaría indefectiblemente a un solo y único propósito: la defensa de su interés económico. Es por esto que no valoraremos directa y genéricamente el móvil económico, sino que enunciaremos las distintas formas que éste pudo revestir:

1. Una de las principales funciones de los cuadros directivos de las empresas mineras es la de coartar la formacis ro de núcleos sindicales en su entorno territorial que puedan promover la organización de movi- 
mientos huelguísticos o reivindicativos. Una huelga general o un paro parcial, una solicitud de aumento salarial o de seguro laboral, puede provocar en la empresa bien una paralización de las actividades industriales, bien una inversión extraordinaria imprevista: en cualquier caso, una contracción del beneficio. El control de la vida societaria de la cuenca minera deja de ser una cuestión de régimen interno cuando se necesita que el juez clausure un centro sindical, que el Gobernador civil ilegalice un sindicato o que un Ayuntamiento obstaculice el normal desenvolvimiento de las asociaciones obreras.

2. Las compañías mineras, por otra parte, son conscientes de la necesidad de frenar el desarrollo de los partidos politicos antidinásticos (republicano y socialista) por una triple razón: en primer lugar, porque éstos: actúan como sostén de las asociaciones sindicales; en segundo lugar, porque su presencia en los Ayuntamientos de la zona puede ser una seria amenaza para la hegemonía de la empresa y, finalmente, porque la defensa del turno dinástico y de las candidaturas monárquicas coloca a las compañias en una óptima posición respecto al Gobierno para emprender cuantas peticiones y negociaciones sean necesarias.

3. La defensa directa de los intereses económicos de las compañías mineras únicamente puede llevarse a cabo implicando a las fuerzas políticas que, dentro del sistema caciquil, por su naturaleza, actúan como redistribuidoras del favor y el beneficio. En un principio, a raíz de su establecimiento en 1873, la principal batalla económica librada por las compañías parece haber sido la competencia con los terratenientes de la comarca, agricultores o ganaderos, perjudicados por los sistemas de calcinación de mineral al aire libre empleados por las compañías, especialmente por la Río Tinto Company. Una vez que el uso industrial del territorio se impuso, las compañías buscaron con su ingerencia en las instituciones políticas obtener ventajas directas: rebaja de aranceles, facilidades portuarias y financieras, monopolio de líneas férreas, abastecimientos, etc... Obligada por estas prioridades, la Compañía de Río Tinto, por ejemplo, llegaría a establecer una relación umbilical con el máximo representante político de la provincia, Manuel de Burgos y Mazo, así como con algunas otras instituciones provinciales.

4. Las compañias mineras -de forma destacada, las grandes compañías extranjeras- plantean su existencia como una lucha a cuerpo con los caciques de la comarca destinada a preservar su correspondiente parcela de poder político. En consecuencia, las empresas mineras tratarán de frenar el acceso de la influencia caciquil a las instituciones político-administrativas de la cuenca minera, copando ellas mismas con sus «recomendados: y candidatos el mayor número posible de cargos. Analizando la correspondencia entre caciques alojada en el Archivo Privado de José 
María Ordóñez Rincón, terrateniente de la localidad de Higuera de la Sierra que organizó en los años ochenta del siglo XIX una Liga Anti-Humista contra las compañías calcinadoras, podemos percibir con claridad meridiana la consciencia de enfrentamiento que existe en todos ellos. Así, no es poco frecuente encontrar alusiones a ala dominación minera", a esas "empresas que son las que mandan. $O$ a la gestión excepcionalmente conjunta de las compañías que pretenden incapacitarnos a uno de los tres concejales que hemos sacado en la elección. ${ }^{3}$. El enfrentamiento entre caciques y compañías, saldado con los violentos sucesos de 1888, parece haber dejado como secuela hasta bien entrado el siglo XX una irreconciliable enemistad, cuyo campo de batalla acabó siendo la política.

5. El control de la política comarcal es el medio más eficaz de tener una baza que ofertar al Gobierno a cambio de otras ventajas, de tal manera que se llega a establecer un verdadero pacto -no siempre tácitocuyos términos son el intercambio de votos y tranquilidad pública por un trato económico favorable.

Expuestos quedan los móviles de la acción política. Nos resta concretar sus ámbitos y precisar sus procedimientos.

\section{LOS AMBITOS DE ACTUACION POLITICA}

Como es lógico, la amplitud y multiplicidad del poder político de las compañías mineras onubenses estuvo en consonancia con la magnitud de éstas y su importancia proporcional en el contexto de la economía provincial y nacional. Difícilmente podríamos equiparar, en este sentido, la extensión de los contactos con que funcionaba la Río Tinto Company con la exigüidad de la acción política en que se movían compañías como la Sociedad Anónima de Buitrón o la de Hijos de Vázquez López.

En cualquier caso, si acotamos un período concreto -la Restauración en su etapa del siglo XX- y sistematizamos globalmente las distintas instancias controladas por el sector minero de la provincia de Huelva, nos encontraremos con que los ámbitos de actuación política de estas empresas abarcan desde la estricta esfera de lo local hasta los resortes de la política nacional pasando, obviamente, por la implicación en la evolución política de la provincia.

A un contacto estrecho con las altas cúpulas de la política española sólo parece haber llegado la poderosa Compañía de Río Tinto que, como veremos más adelante, mantuvo en su nómina a diputados en Cortes e instituyó la figura de su representante oficial ante el Gobierno. Largamente

(3) [A]rchivo [P]rivado [O]rdóñez [R]incón, Cartas a Ordóñez Rincón de Antonio Tello (20-81892 y 25-7-1892) y de R. Jimeno, secretario del Ayuntamiento de Calañas (14-12-1889). 
se especuló en su época, desde los medios de comunicación, sobre el alcance de este maridaje con los círculos gubernamentales, llegándose a establecer, incluso, conexiones entre la gestión de la Compañía y el nombramiento como Ministro de Burgos y Mazo en 1915 y; lo que es más. grave, entre la presión de dicha empresa y la destitución del Ministro de Hacienda, Urzaiz, dos días después de que éste firmase en 1916 dos Reales Ordenes gravando la exportación de piritas y restableciendo los derechos arancelarios para la venta de piritas de cobre. Acusación ésta que, más recientemente, han recogido también Fernández Almagro y Calero Amor 4 .

Sin llegar a estos extremos, probablemente incomprobables, lo que sí es cierto es que la Compañía tuvo línea directa con el Presidente del Consejo de Ministros y que, valiéndose de este trato preferencial, gestionó asuntos de considerable importancia. En 1918, por ejemplo, la correspondencia enviada a Antonio Maura por Walter J. Browning, director general de la Compañía de Río Tinto desde 1908 , se dirigió, principalmente, a solicitar el envío de tropas a la cuenca minera para contener la agitación obrera, requerir un envío de harina para garantizar el abastecimiento de la población y obtener permiso para realizar una emisión extraordinaria de obligaciones hipotecarias cotizables en las Bolsas nacionales.

La formulación de esta última petición es, quizás, la que más elocuentemente refleja el tipo de relación establecida entre ambos poderes: el económico, representado por la Compañía, y el político, representado por Maura.

$\because . . V d$. es tan digno e ilustre Presidente, hasta el punto de que no dudaría en conceder a la Compañía que represento el permiso mencionado que, si por el momento resolvería el problema de la depreciación de las libras esterlinas, también solucionaría para el Gobierno otro de mucha gravedad como es el del orden público perturbado al tener que reducir la Compañía sus trabajos.s.

Una cuestión financiera de esta índole exigía que la Compañía extremara su insistencia mediante contactos personales de Browning con los Ministros competentes en el tema:

-Hace dos semanas, cuando tuve el gusto de ver al Sr. Ministro de Estado en San Sebastián, me dijo que había sido a probada por el Consejo de Ministros la solicitud de la Compañía de Río Tinto para la emisión de obligaciones y que me autorizaba para así comunicarlo al Embajador británico y a la vez a mi Compañía, agregando que podiamos tener la

(4) La Provincia (Huelva), 21-3-1915. CALERO AMOR, A. M.: Opus cit., p. 56 y FERNANDEZ ALMAGRO, M.: Historia del reinado de Alfonso XIII. Montaner y Simón, Barcelona, 1934, p. 275. Diario de Sesiones del Congreso, 28-6-1916.

(5) [A]rchivo [M]aura, carta de Walter J. Browning a Antonio Maura, 6-8-1918, leg 89, carp. 31. 
seguridad de que para el día $1^{\circ}$ dé septiembre o antes tendríamos en nuestro poder la Real Orden en este sentido. ${ }^{6}$.

Para los investigadores acostumbrados a manejar la documentación atesorada por los archivos privados de la Restauración los términos anteriores habrán resultado sorprendentemente familiares. Más aún los empleados por Maura en una de sus respuestas:

-...tengo el gusto de comunicarle que en efecto, según prometí a $\mathrm{V}$., interesé a los Ministros de Hacienda y Fomento la solución a la petición presentada al Gobierno por la Compañía de Río Tinto, sin que haya caído resolución inmediata, aunque procuran ellos y procurarán abreviar el desenlace de este asunto. El Ministro de la Gobernación ofreció seguir ocupándose con redoblado ahínco de allanar las dificultades que existen para el abastecimiento en subsistencias de la población minera ${ }^{7}$.

$\mathrm{Al}$ igual que en la mayor parte de las relaciones económico- políticas entabladas por la clase dirigente de la Restauración, el carácter de intercambio de favores preside, como vemos, las relaciones entre la Río Tinto Company y el Gobierno. Un intercambio que ya antes hemos calificado como pacto más o menos tácito y que está presente, igualmente, en lo relativo a las ingerencias de las compañias mineras en el ámbito político provincial.

Al circunscribirnos al espacio provincial onubense, el número de compañías que funcionan como elementos de presión se incrementa. Aunque es difícil cerrar la enumeración, podemos afirmar, al menos, que, junto a la Compañía de Río Tinto, sostuvieron aquí su protagonismo la de Tharsis y la United Alkali. En 1923, la prensa de Huelva más respetuosa con el proceder de las compañías reconocía abiertamente que el triunfo del candidato a Cortes reformista, Marchena Colombo, sólo había sido posible contando con la anuencia de las grandes compañías mineras del Andévalo, sin cuyo apoyo no se hubiera podido compensar, en ningún caso, el débil asentamiento caciquil del reformismo en la cuenca minera ${ }^{8}$. $\mathrm{Y}$ es importante detenerse en este detalle, puesto que, ciertamente, las compañías mineras solían prestar en el distrito de Valverde un apoyo caciquil capaz de conseguir fácilmente la victoria electoral de candidatos cuneros o sin arraigo tradicional en la comarca.

A lo largo de la Restauración y como consecuencia de la pugna entre compañías y población trabajadora, el distrito minero se configuró c mo un distrito políticamente inestable -moderno, según Tusell-y espe-

(6) A.M., Carta de Walter J. Browning a Antonio Maura, 4-9-1918, lege 192.

(7) A.M., Carta de Antonio Maura a Walter J. Browning, 12-8-1918, leg 192.

(8) Vid. PENA GUERRERO, M.A.: El sistema caciquil en la provincia de Huelva. Clase política y partidos (1898-1923). Ayuntamiento de Córdoba, 1993. 
cialmente vulnerable a las distintas coyunturas atravesadas por el poder de las empresas. Sólo el resurgir del sindicalismo obrero a partir de 1913 puede explicar debidamente el repetido triunfo de la candidatura republicana en 1918 y 1919, cuando la autoridad de la Compañía de Río Tinto es cuestionada ampliamente y los obreros cuentan con una organización que les ampara frente a la empresa ${ }^{9}$.

Las raíces de esta intervención política en las elecciones generales de la provincia son, por el momento, difíciles de concretar. En el caso de la Compañia de Tharsis y de la United Alkali no sabemos si es un comportamiento esporádico fruto de una negociación específica con el Gobierno o si es un procedimiento regular decidido por el consejo de accionistas. En cuanto a la Río Tinto Company, ésta última apreciación parece estar confirmada por las propias palabras del representante de la empresa en Huelva, José Sánchez Mora, en una carta publicada en $\mathbf{L a}$ Provincia el 16 de mayo de 1899, al referirse a la actuación de sus directivos en las elecciones celebradas en abril de ese año:

-[La Compañía], a su vez, cumpliendo los acuerdos del Consejo de Administración, los cuales ordenan categóricamente prestar apoyo al Gobierno constituido (sea el que sea) así se lo ofreció a usted, y comunicó a los diversos departamentos las instrucciones oportunas al logro de este propósiton.

La expresa intencionalidad que revelan estas palabras parece estar presente también en lo relativo a la intervención política de las compañías en el ámbito municipal. Como tendıemos ocasión de comprobar en el siguiente apartado, el círculo de empresas vinculadas a la política local vuelve a ampliar aquí su radio, englobando no sólo a las grandes sociedades mineras españolas o extranjeras, sino también a pequeñas entidades empresariales constituidas por un número escaso de accionistas o concesionarios. Dos nos parecen los fundamentos más importantes de esta vigilante implicación política: por una parte, el hecho de que las mismas fuerzas políticas turnantes de la provincia están interesadas en conseguir la colaboración caciquil de las compañías para decidir el voto de una fracción importante del electorado y, por otra, el propio interés de las compañias en ejercer un constante control sobre las corporaciones municipales de su área de influencia.

(9) TUSELL, J.: Oligarquia y caciquismo en Andalucia (1890-1923). Planeta, Barcelona, 1976, pp. 227 y ss.

Sobre la organización del movimiento sindical en la cuenca minera puede verse CALERO AMOR, A.M.: Opus cit.; GIL VARON, L.: Opus cit.; CASTRO DE ISIDRO, F.: .Entre cobre y oro. Radicales y socialistas en la huelga general de Riotinto. Historia Social, num. 5; RIOJA BOLAÑNOS, A.: Las luchas sociales en Riotinto y Nerva. Nervae, nums. 5-8, mayo, 1985; LUNAR, F.: A cielo abierto. De Riotinto a Norteamérica. México, 1956 (ed. de Senabra, 1991). 
El análisis realizado por los consejeros de la Río Tinto Company que visitaron las minas en 1904 es, en este orden de cosas, muy significativo. La necesidad de intervenir con decisión en la vida política local se argumenta por varias razones, - entre ellas dominar las actitudes exaltadas durante una huelga, conseguir una administración económica de los asuntos municipales y mineros (y, en consecuencia, unos impuestos locales razonables) amén de para lograr una gestión eficaz de las cuestiones sanitarias ${ }^{10}$.

Semejante valoración de las necesidades políticas de la Compañía llegaba tarde, habida cuenta de que ya en 1888, quince años después de la compra de las minas, Romero Robledo había expuesto en el Congreso el "nepotismo* con que la empresa colocaba a sus empleados en la administración municipal:

....el Ayuntamiento de las Minas de Río Tinto se compone, con excepción de dos concejales, de dependientes de las empresas. El alcalde es capataz de una de las minas; el teniente de alcalde, jefe de estadística de otra de las minas, y todos los concejales, a excepción de dos, dependientes de las minas; $y$, naturalmente, aquellos funcionarios no eran, no son, no pueden ser ante la ley los representantes de los intereses de los pueblos, sino los representantes de los intereses de las empresas, porque por representar a las empresas cobran sueldo" ${ }^{11}$.

Manipulación de resultados electorales y designación de los alcaldes que debían ser nombrados por Real Orden son, a primera vista, los mecanismos básicos empleados por las compañías para disponer a su antojo de las corporaciones municipales. Șobre ello, tendremos ocasión de volver.

\section{LOS INSTRUMENTOS DE INTERVENCION}

A tenor de lo expuesto en las páginas precedentes, parece incuestionable que las compañías mineras de la provincia de Huelva se configuraron, a lo largo de todo el período de la Restauración, como un grupo de poder económico de gran influencia en el desenvolvimiento de la política provincial. Sociedades extranjeras las más importantes y de entidad variab!e las españolas, muchas de estas compañías fueron capaces de arrebatar a los caciques terratenientes de su entorno rural el poder fáctico sobre los hombres y las instituciones que éstos venían disfrutando desde un momento -aún difícil de precisar- que bien podría remontarse al establecimiento del régimen isabelino.

(10) AVERY, D.: Opus cit., pp. 284 y s.

(11) Diario de Sesiones del Congreso, 17-2-1888. 
Hemos analizado hasta ahora, en la medida que las fuentes y los hechos lo permiten, los móviles de esta intervención política y sus ámbitos de acción. Conviene ahora centrar nuestro interés en los procedimientos concretos, los instrumentos precisos que las compañías mineras arbitraron para establecer y mantener su preeminencia sobre el territorio.

Ahora bien, antes de abordar de lleno este apartado, consideramos oportuno realizar algunas observaciones sobre la propia configuración de las compañias que, a nuestro juicio, condicionan sus hábitos y modos de intervención política. En primer lugar, debemos tener en cuenta que, a diferencia de las empresas navieras ayamontinas o de las viticultoras del Condado, normalmente de carácter familiar, las compañías mineras del Andévalo onubense -al menos las de mayor magnitud, objeto de nuestra atención- son sociedades anónimas, constituidas por un número indeterminado de accionistas, impersonales, por lo tanto, desde un punto de vista político, e incapaces de colocar directamente en las Cortes, la Diputación o los Ayuntamientos a sus propietarios o cuadros directivos. Por otro lado, las más interesadas en la intervención política son sociedades extranjeras, naturalmente extrañas al espacio comarcal en el que se asien$\tan$ y que, en consecuencia, no pueden recurrir como el resto de los caciques de la provincia a vínculos de carácter familiar o clientelar asentados por la tradición y el paso de los años. Su poder no parte de unas raíces previas en la cuenca o de una reconocida actividad benefactora. Más bien al contrario, estas empresas mineras se caracterizan por su reciente implantación y por un comportamiento agresivo y especulador que, desde el principio, las coloca ante la población como la antítesis del cacique bueno, redistribuidor de beneficios y protector de su círculo inmediato.

Las compañías fueron conscientes de que carecían de esta positiva imagen pública y de que su propia constitución era un pesado lastre para mantenerse a flote en la marea política de la Restauración. Debían, no obstante, responder satisfactoriamente a la defensa de sus.intereses y, en efecto, supieron hacerlo utilizando sus propias armas y recursos, de tal forma que, finalmente, disfrutaron de un poder no ya equiparable al de cualquier otro cacique de la provincia, sino incluso superior. Desde el mantenimiento de representantes oficiales y diputados a sueldo, hasta el ejercicio directo de la coacción electoral, pasando por el control de las instituciones político-administrativas de la provincia, sus procedimientos de intervención política componen una amplia galería de comportamientos caciquiles que nos ofrece un nuevo y distinto perfil del funcionamiento del sistema político de la Restauración española. 


\subsection{Diputados a sueldo y representantes oficiales}

La propia concepción de explotación colonial en que se fundaba la mayor parte de estas sociedades hacía que su clase directiva fuera eminentemente extranjera y que, por lo tanto, estuviera totalmente excluida de cualquier posibilidad de intervención directa en los asuntos políticos españoles $u$ onubenses. De esta limitación se desprendió, de forma inexcusable, la necesidad de mantener en nómina un nutrido grupo de individuos de nacionalidad española que actuaran como sus testaferros, dedicados -como políticos profesionales o como representantes oficiales de las compañías- a defender los intereses de éstas ante el Gobierno nacional o provincial.

Este esquema de intervención política "oficializada" fue especialmente utilizado por la Río Tinto Company Limited que, desde 1874, sólo un año después de su establecimiento en Huelva, consideró imprescindible contar con un político español a su servicio, que agilizase la tramitación de permisos para la puesta en marcha de la explotación y le asesorase en todo lo concerniente a la relación con otros políticos nacionales. El primero de estos diputados a sueldo -Daniel Carballo y Codesillo-, al que la Compañía abonaba una minuta de 1.200 libras anuales, renunció en 1889 por desavenencias con la dirección y fue remplazado por Enrique Bushell y Laussat, diputado a Cortes por Valverde, cuya minuta anual de 1.000 libras sería aumentada en 500 más como pago por su colaboración en la rescisión del decreto que prohibía las calcinaciones de mineral al aire libre que venía realizando la Compañía ${ }^{12}$.

Hasta 1896, Bushell permaneció al servicio de la Río Tinto Company como representante político de ésta y gestor de sus intereses. A lo largo de estos años, la Compañía extremó su celo en conseguir que el diputado conservara su escaño frente a otros candidatos electorales. Interés denodado éste que llevó incluso al consejo directivo a autorizar, en 1893, una partida de 2.000 libras para garantizar el control del electorado valverdeño y afianzar así su triunfo. El relevo de Bushell llegó, como hemos dicho, en 1896 , fruto de las propias discrepancias entre éste y el consejo a la vez que del ofrecimiento realizado por el onubense Manuel Martín de Oliva, marqués de Oliva, para que su hijo Juan obtuviese el escaño de Valverde a cambio de servir a la Compañía 'como firmes aliados en las Cortes y en las negociaciones con el Gobierno ${ }^{13}$. Entre 1898 y 1923, la leva de diputados onubenses como representantes políticos parece haberse atenuado considerablemente $o$, al menos, se realizó con una gran discreción. La Compañía, como ya se ha visto, prefirió apoyar al candidato

(12) AVERY, D.: Opus cit., pp. 279 y s.

(13) Ibidem, pp. 281-2 y 285. 
ministerial, fuese cual fuese, optando por una representación oficial políticamente neutra, desligada de las pasiones de la política provincial.

Lo que sí mantuvo la Compañía en todo momento, desde su misma constitución, fue la figura de su representante oficial, normalmente un abogado de profesión que debía atender al asesoramiento jurídico de aquélla pero que, en realidad, funcionaba también como un representante político. Desde 1873, esta misión recayó sobre el madrileño Gabriel Rodríguez que, según Avery, traspasó el cargo a su hijo Antonio en 1901. Un nuevo giro en la representación de la Compañía habría de producirse en 1904, cuando el consejo decida de nuevo separar lo estrictamente jurídico de lo político y deposite esta última responsabilidad en el economista José Valero Hervás ${ }^{14}$.

Gaditano de nacimiento pero muy vinculado desde su adolescencia a la provincia de Huelva, Valero Hervás reunía en su persona un conjunto de características que encajaban perfectamente en lo que la Compañía debía entender como el perfil ideal de su representante: era doctor por la Universidad de Londres en Ciencias Económicas y Políticas y acuñaba una extensa experiencia en asuntos financieros, poseía estrechos contactos con las primeras entidades mercantiles de la capital inglesa y a la vez gozaba en España de un considerable prestigio. Como político, Valero había dado ya sus primeros pasos; con el tiempo, su condición de concejal en el Ayuntamiento de Madrid y su escaño por el distrito de Fraga, en Aragón, acabarían convirtiéndolo en un favorecido interlocutor con el Gobierno y con el resto de las fuerzas vivas del país. Por lo demás, una última característica venía a adornar la idoneidad de Valero. Sin ser onubense, se le consideraba como tal y su ingerencia en los asuntos que implicaban a la provincia no despertaba apenas ningún recelo's.

Entre la Compañía, el cacique provincial Burgos y Mazo y el propio Valero llegaría a establecerse, más adelante, una estrecha relación triangular, que el rotativo onubense La Cría traduciría en los siguientes términos:

-El sr. Valero Hervás es el representante de la Compañía de Río Tinto desde hace mucho tiempo y la Compañía de Río Tinto es casi bechura de Burgos. Luego, Mr. Browning y Burgos están de acuerdo y por tanto Valero Hervás a los dos representa ${ }^{16}$.

Así las cosas, no debe extrañarnos que la elección de Valero en 1923 como senador por la provincia de Huelva fuese festejada por los conservadores onubenses como el remate perfecto de una situación de armonía y

(14) Ibidem, p. 282.

(15) SANCHEZ DE LOS SANTOS, M.: Las Cortes de 1914, p: 747.

(16) La Cria (Huelva), noviembre, 1916. 
de conveniencias recíprocas. A nadie se le ocurrió entonces, por supuesto, atacar su candidatura como se había atacado antes la de otros cuneros.

Pero tan interesante como reconstruir su biografía, resulta profundizar en la forma de actuación de este representante oficial de la Compañía. Aunque Avery insiste en ponerlo a su servicio desde 1904, parece evidente que dos años antes Valero ya funcionaba como *representante general en España. de la Río Tinto Company gestionando ante el Gobierno asuntos de índole estrictamente política ${ }^{17}$. Así lo atestigua, al menos, la correspondencia cruzada con el entonces presidente del Consejo de Ministros, Antonio Maura.

Es muy probable que las controvertidas elecciones municipales de 1903 fueran el primer campo de batalla en el que Valero hubo de demostrar su destreza política. Según comenta Avery en su libro, antes de llevarse a cabo los comicios, Valero ya había gestionado con el ministro de la Gobernación el nombramiento de alcaldes para los pueblos de Valverde y Zalamea, de tal manera que se designase a individuos afectos a la Compañía y propuestos por Mr. Carlyle, a la sazón director general de ésta, desestimando la recomendación política de los diputados onubenses Burgos, Limón e Hidalgo ${ }^{18}$. Sin embargo, el problema no debió terminar ahí.

Una vez celebradas las elecciones el 8 de noviembre, y quedando pendiente el nombramiento de los nuevos alcaldes, Valero volvió de nuevo a desplegar sus artes para que las alcaldías vacantes de la cuenca minera no recayesen en individuos shostiles* a la Compañía, partidarios de los caciques provinciales.

En la primera carta dirigida a Antonio Maura que nos consta, José Valero solicitó el mantenimiento de los *actuales* alcaldes, apreciándolos "personas de intachable reputación y de integridad notoria", que estarían siempre incondicionalmente a disposición del Gobierno, de manera especial a la hora de garantizar el triunfo de los candidatos ministeriales encasillados por el distrito de Valverde ${ }^{19}$. Sucesivas cartas, hasta completar una copiosa correspondencia a caballo entre 1903 y 1904 , volvieron a insistir en esta misma propuesta, unas veces dirigiéndose directamente a Maura, otras buscando el intermedio de su secretario Prudencio Rovira. $\mathrm{El}$ argumento recurrente en todas ellas es que la única forma de preservar la tranquilidad política en la comarca y proteger la acostumbrada armonía entre Gobierno y Compañía era mantener en sus cargos a los citados alcaldes, rechazando taxativamente la propuesta presentada a Maura en

(17) SANCHEZ DE LOS SANTOS, M.: Opus cit., p. 747.

(18) AVERY, D.: Opus cit., p. 284.

(19) A.M., Carta de José Valero a Antonio Maura, s.f., leg 429 , carp. 20. 
diciembre de ese mismo año por los diputados de Huelva, Burgos y Mazo, Hidalgo y Jiménez ${ }^{20}$.

Ciertamente, fue necesaria más de una carta para que la petición de Valero quedase debidamente atendida. Las ampollas levantadas en la dignidad de los diputados onubenses pesaron menos, obviamente, que las tajantes palabras de la Compañía voceadas por Valero. Uno de los desairados más ofendidos, Sancho Hidalgo, envió a Maura una ofuscada misiva en la que exponía sus agrias impresiones sobre el tema:

*...Si los intereses en todos los órdenes han de estar supeditados a las grandes Compañías Extranjeras, si hemos de pertenecer a una colonia inglesa, valía más que tuvieran Vdes. el valor de la franqueza (...). Los alcaldes nombrados para Nerva y Riotinto son asalariados de la Compañía, incapaces de administrar y proclaman por lo supeditados y obedientes el favor a que deben el cargo y la mezquina representación que en éste se conceden a las gentes que en él valen y que tienen independencia e imparcialidad para proceder según demanda la justicia en los graves conflictos que suelen promoverse contra las Compañías y sus obreros. (...) Las elecciones de ambos pueblos han sido anuladas por la Comisión Provincial y los alcaldes nombrados son concejales electos, imposibilitados para tomar posesión en $1^{9}$ de enero ${ }^{21}$.

En su contestación, Maura reprendió el apasionamiento de Hidalgo y le aseguró que la empresa no había realizado ninguna recomendación, procediendo el Gobierno en atención a las "circunstancias excepcionales" de la cuenca minera así como a sla magnitud de los intereses sociales y la muchedumbre de gentes sobre quienes la empresa industrial aludida en su carta tiene decisivo influjo.22.

En cualquier caso, no dejaba de ser cierto que, tal y como había indicado Hidalgo, las elecciones municipales de Riotinto y de Nerva habían sido anuladas por la Comisión Provincial de Huelva en su sesión del 30 de diciembre de 1903. La gravedad de las reclamaciones electorales interpuestas por algunos votantes parecía ser la razón prioritaria de esta anulación ${ }^{23}$. Una última carta de Valero a Maura, ya en marzo de

(20) A.M., Carta de Manuel de Burgos y Mazo a Antonio Maura, s.f., leg ${ }^{\circ} 429$, carp. 20 . Se conservan en este mismo lugar los estadillos realizados por Maura al objeto de clarificar el problema de las elecciones municipales en la cuenca minera. En ellos aparecen dispuestas tres columnas en donde se hacen constar, respectivamente, los nombres de los Ayuntamientos en litigio (Valverde, Zalamea, Minas de Riotinto, Nerva, Alosno y Calañas), los recomendantes (Manuel de Burgos y Mazo, Sancho Hidalgo, Juan Mateo Jiménez o la Compañía de Río Tinto, según los casos) y los distintos recomendados.

(21) A.M., Carta de Sancho Hidalgo a Antonio Maura, 30-12-1903, lege 429, carp. 20.

'(22) A.M., Carta de Antonio Maura a Sancho Hidalgo, 2-1-1904, leg ${ }^{2} 429$, carp. 20.

(23) [A]rchivo [D]iputación [P]rovincial de [H]uelva, Comisión Provincial, 30-12-1903; libro 143. 
1904, acabaría de determinar esta batalla política con la solicitud de que el Ministro de la Gobernación ratificase la validez de los comicios para que no triunfase sla política de pasiones que algún diputado por aquella Provincia desea a toda costa impere. ${ }^{24}$.

Ahora bien, este tipo de correspondencia privada no sólo nos relata la gestión concreta del representante de la Compañía en un caso particular de intervención política, sino que nos permite también analizar los argumentos que ésta esgrime en la defensa de sus intereses y el tipo de relación que establece con el Gobierno.

El recurso a terceros debió ser, sin duda, algo bastante frecuente. En el mismo mare magnum epistolar que hemos registrado constaba la intercesión del Gobernador civil de Zaragoza, Luis Soler, a favor de la Río Tinto Company, actuando como garante de Valero ante Maura con el aval de su amistad personal y reiterando los términos ya expuestos por aquél ${ }^{25}$.

Por otro lado, releyendo las peticiones de Valero, cuatro parecen haber sido los principales planteamientos de la Compañía para justificar su intervención política: el primero de ellos, considerar que esto se venía haciendo desde tiempo inmemorial ${ }^{26} \mathrm{y}$, luego, entender que el mantenimiento de su autoridad política era condición sine qua non para garantizar en la cuenca minera el orden público, el triunfo de los candidatos monárquicos ministeriales y el control sobre los focos republicanos y socialistas, siempre prestos a absorber el voto de la masa obrera. De ser necesario, aún podía añadirse a esto el óptimo funcionamiento de las administraciones municipales y la prosecución a buen ritmo de los trabajos industriales. Argumentos, entre otros, que Valero enumeró a Prudencio Rovira con extremada pulcritud:

. $1^{\circ}$ La Compañía ha estado y está al servicio del Gobierno.

$2^{\alpha}$ Los Ayuntamientos electos de Riotinto y Nerva lo están incondicionalmente, así como los actuales Alcaldes, que fueron los que influidos por nosotros dieron la elección al Gobierno, eligiendo al Sr. Sancho Hidalgo en las últimas elecciones para diputados a Cortes.

$3^{\circ}$ El Gobierno no puede perder nada respetando esos Alcaldes Conservadores que no tienen prejuicio alguno contra la Compañía ni los intereses mineros de aquella región: por el contrario, de acuerdo con la Compañía, como siempre se ba becho, no tendrá nunca el Gobierno molestia ni dificultad alguna en aquellos pueblos.

$4^{\circ}(\ldots)$ Si algún político (...) quisiera imponer allí Alcaldes hostiles a la Compañía, ésta perderá toda fuerza moral y todo prestigio y no podre-

(24) A.M., Carta de José Valero a Antonio Maura, 24-3-1904, leg 108.

(25) A.M., Carta de Luis Soler a Antonio Maura, 26-12-1903, leg ${ }^{\circ} 429$, carp. 20.

(26) A.M., Carta de José Valero a Antonio Maura, s.f., leg 429. 
mos ayudar al Gobierno en lo futuro, por grandes que fueran nuestros esfuerzos para conseguirlo, porque aquella población es de republicanos exaltados y socialistas peligrosos, que sólo la Compañía puede mantener en actitud pacífica y sólo la Compañía puede hacer que se elijan Ayuntamientos y diputados monárquicos. (...) La Compañía de Río Tinto que tantos servicios ha prestado a los Gobiernos, evitando con su consejo que los obreros votasen a los republicanos y que es siempre ministerial de todo Gobierno, conservador o liberal ¿pide demasiado...? ${ }^{27}$.

Después de digerir líneas como éstas, no debe extrañarnos que Maura complaciese de buen grado a una Compañía que, en definitiva, amenazaba con abandonar los 12.000 votos de su plantilla minera a la seducción del republicanismo.

\subsection{La creación de una falsa dependencia}

Inmersas en un sistema político como el de la Restauración, basado en la reciprocidad del favor, la generación de lazos clientelares y el control de una amplia población mayoritariamente desmovilizada y analfabeta, las compañías mineras onubenses fueron conscientes de la necesidad de crear en su entorno unos vínculos que las colocaran en un posición de autoridad y preeminencia.

Al igual que otros caciques de la provincia, pretendían convertirse en el núcleo gestor de una clientela que les debiese respeto y obediencia, pero, a diferencia de ellos, no disponían de una implantación similar ni de relaciones familiares ni de una personalidad carismática y estable a su cabeza. Las sociedadés mineras debieron, por lo tanto, improvisar lo que naturalmente no poseían y generaron sus propias redes de poder.

La más básica e importante de todas se derivaba del propio hecho de suministrar trabajo, situación que les permitía disponer de un buen número de individuos vinculados a ellas laboralmente y dispuestos a acatar sus designios a fin de asegurar su supervivencia. El reforzamiento de esta relación de poder con otras más complejas parece depender directamente de la propia magnitud de la empresa minera. Debe ser, por ello, que, una vez más, la Compañía de Río Tinto nos ofrece, en este sentido, la cota máxima.

El control de la Río Tinto Company sobre la población se realizó, esencialmente, a dos niveles: a título particular, decidiendo respecto al trabajo, vivienda, sanidad y ocio de sus obreros ${ }^{28}$, y a título colectivo,

(27) A.M., Carta de José Valero a Prudencio Rovira, 24-12-1903, leg 429, carp. 20.

(28) Según Barriobero, a los obreros de las minas se les controlaba desde la asistencia a los mítines o reuniones hasta la hora de estar en casa. Diario de Sesiones del Congreso, 8-
11-1914 y 18-4-1918. 
ejerciendo, a través de las corporaciones municipales, una supervisión exhaustiva de todo lo relativo a la vida de las localidades mineras. Los dos focos obreros por excelencia -Minas de Riotinto y Nerva- dan buena cuenta de ello.

En el primer caso, la relación de dependencia entre municipio y empresa se derivaba de las propias condiciones de la :Ley de Venta de las Reales Minas de Río Tinto,29, en virtud de la cual la Compañía era propietaria de todo lo construido y por construir-del edificio capitular, incluso- y, en consecuencia, debía hacerse cargo de buena parte de las competencias que, de no ser así, hubieran correspondido al Ayuntamiento. La Compañía sufragaba el alumbrado de las calles, la conservación de caminos, los servicios sanitarios, educativos y administrativos, disponía sobre la construcción y derribo de viviendas, mantenía el matadero municipal, el suministro de agua, el cementerio y hasta el lavadero público ${ }^{30}$. Obviamente, esta situación contractual liberaba a la Corporación de Minas de Río Tinto de cargas muy onerosas, permitiéndole disponer de ventajas económicas e infraestructurales desconocidas en otras localidades de su entorno, pero también hacía al municipio acreedor de una forma especial de servidumbre, rayana en el constante agradecimiento y la falta absoluta de libertad.

El caso de Nerva es, si cabe, más llamativo, puesto que en él no rigen de forma tan decisiva las condiciones de venta de las Minas: la Compañía sólo es propietaria de una parte del territorio municipal y, sin embargo, sigue controlando importantes facetas de la vida local. La propiedad sobre las infraestructuras más elementales del municipio es, desde luego, el rasgo más destacado. Hasta 1930, al menos, la empresa de Río Tinto mantuvo la propiedad sobre los manantiales y fuentes de donde se obtenía el suministro de agua potable a la población nervense, así como de las tuberías y canalizaciones precisas para ello. Normalmente, la cesión de estas instalaciones se realizaba en calidad de usufructo, con lo cual se generaba una dependencia respecto a la Compañía que ni siquiera podía ser salvada o amortizada económicamente. La instalación de fuentes y baños públicos fue, igualmente, un gesto desprendido de la Compañía, del mismo modo que su colaboración en algunas obras públicas, como el montaje del alumbrado público.

Guiado por una manifiesta voluntad de *cooperar a toda obra que redun te en beneficio general de los vecinos de Nerva y muy especialmente a los que trabajen en los diferentes servicios de la Compañía, su director general, W.J. Browning, organizó eficazmente el abastecimiento de pescado y verduras a precio de costo y la puesta en funcionamiento

(29) GIL VARON, L.: Opus cit., p. 131.

(30) AVERY, D.: Opus cit., p. 240. 
del cinematógrafo y la cocina económica en 1920. A lo largo del primer cuarto de siglo, no faltaron tampoco las buenas palabras. En alguna ocasión, Browning llegó a proponer al Ayuntamiento de Nerva la venta de determinados servicios prestados por la Compañía a cambio de una elevada suma de dinero en efectivo o su permuta por algunos terrenos baldíos del municipio. En uno y otro caso, era evidente que el patrimonio nervense no estaba en condiciones de acometer esta inversión.

En definitiva, y al igual que ocurría con Minas de Riotinto, Nerva fue acumulando progresivamente una impagable deuda moral con la Río Tinto Company agravada, en este caso, por una paralela deuda real: la derivada de las compras de materiales de construcción a la Compañía.

Que ésta supo saldar sus cuentas por otros medios lo demuestra fehacientemente una carta del director general de la Compañía al alcalde de Nerva en la que aquél se niega a aceptar que dos concejales que trabajan en la empresa se ausenten de la mina durante un par de horas, un día a la semana, para proceder a la inspección del Matadero y del Mercado municipal ${ }^{31}$.

\subsection{La coacción electoral directa}

No cabe duda de que, entre todos los instrumentos de intervención política atribuibles a las compañías mineras de la provincia de Huelva, éste fue el más generalizado, frecuente y denostado de todos. Es más, da la impresión de que se trataba de un comportamiento consustancial a este tipo de sociedades desde el momento en que sobrepasaban su minoría de edad y se convertían en organizaciones empresariales de alto nivel.

Si atendemos a las palabras publicadas por El Alcance en 1899, nuestra impresión se confirma, puesto que en ellas se calificaba la coacción al electorado como una iiritante y tradicional costumbre de las compañías mineras para carantizar la relación cordial con los ministerios ${ }^{32}$. Había, no obstante, otras versiones atenuantes entre la prensa onubense. La Provincia, portavoz oficioso de la Rio Tinto Company según la prensa socialista, defendía el tono respetuoso con que la dirección de la empresa aconsejaba a sus obreros el voto progubernamental, negando la existencia de presiones electorales fraudulentas y aclarando, en última instancia, que era la Compañía la que sufría amenazas y coacciones por parte del Gobierno para "que llevasen formados, y bajo la dirección de sus respectivos capataces, a los obreros a votar las candidaturas ministeriales". Este diario onubense consideraba impensable que los directivos, shijos de un pueblo

\footnotetext{
(31) Archivo Municipal de Nerva, Correspondencia entre Walter J. Browning y el alcalde, 1902-1929, lege 77.

(32) El Alcance (Huelva), 16-5-1899.
} 
verdaderamente libre y sumamente respetuoso del sufragio", se hubiesen sumergido en el slodazal. caciquil de la política española ${ }^{33}$.

En esta opinión abundaba también Diario de Huelva, que extendía la inhibición política de la Compañía incluso a las elecciones municipales comentando: ‘A qué, pues, mezclar en la danza a una Compañía inglesa, a la cual le importa un bledo el color político de los concejales en aquellos municipios? ${ }^{34}$.

No obstante, si dejamos a un lado los comentarios de este tipo de prensa y nos ceñimos a las fuentes de que disponemos no podemos sino reconocer que la coacción electoral se ejerció con profusión en toda la cuenca minera tanto en elecciones municipales, como en elecciones provinciales y generales. Los primeros testimonios documentales que hemos podido recoger datan de 1891.

Presentada en una de las mesas electorales de Zalamea, el $1^{\circ}$ de febrero de ese año, la reclamación de varios electores de la sección tercera, además de denunciar que la votación se había verificado en un "pasadizo... sin más luz que la de la puerta de entrada" y que se habían realizado arbitrarias anulaciones de votos, declaraba lo siguiente:

“...las candidaturas (...) han sido repartidas a los electores dentro del local, a presencia de la mesa y a muy corta distancia de ella, sin duda para asegurar el éxito de la coacción que con los obreros de Riotinto se viene ejerciendo, de despedirlos de sus trabajos si no apoyan la candidatura ministerial. ${ }^{35}$.

Aparte del valor intrínseco de estas líneas, resulta especialmente significativo que la mesa desestimase la reclamación por inexacta, negándose a incluirla en acta. En 1893, las protestas electorales se reprodujeron en Zalamea. Recordemos que en este año estaba en juego la victoria del candidato y representante político de la Compañía, Enrique Bushell y Laussat, frente al Conde de Gomar. Las presiones electorales debieron incrementarse notablemente durante estos comicios, pues fueron tres las reclamaciones formuladas por los votantes, si bien sólo una llegó a admitirse en acta. Por lo demás, todo demuestra que los procedimientos coactivos se habían enriquecido: el juez municipal colaboró recomendando que se votase a Bushell, se colocaron grupos de individuos impidiendo el acceso a los colegios y se detuvieron a algunos interventores. Del texto se desprende que en dos años la coacción se había organizado meticulosamente:

-...la gran presión ejercida por la Compañía de Río Tinto sobre sus operarios, cohibiéndolos con la amenaza de despedirlos del trabajo y obligándolos a votar candidatura determinada; y a cuyos electores se ha hecho venir

(33) Huelva Libre (Huelva), 9-12-1916 y La Provincia (Huelva), 12-5-1899.

(34) Diario de Huelva, 18-2-1922.

(35) [A]rchivo [M]unicipal de [Z]alamea, Expedientes electorales, $\operatorname{leg}^{\circledR} 809$. 
en grupos hasta las puertas del colegio, con'sus capataces y listeros a la cabeza, sin duda para el mejor logro de sus fines, impidiendo que sus operarios electores ejerciten libremente sus sagrados derechos de elección.36.

Ahora bien, estos dos casos aislados, feliz excepción informativa de unos archivos municipales normalmente desprovistos de documentación èlectoral, poco nos aclaran sobre el carácter sistemático de la coacción ejercida por las compañías mineras onubenses.

Si examinamos las reclamaciones electorales presentadas ante la Comisión Provincial de Huelva entre 1898 y 1923, esta misma sistematización apuntada puede ser puesta en entredicho. A lo largo de estos 25 años, sólo seis expedientes electorales incluyeron entre sus protestas la denuncia de presiones efectuadas por este tipo de empresas. La cifra, que obviamente es baja, no deja, a nuestro juicio, de ser significativa. Habida cuenta de que las competencias de la Comisión se refieren exclusivamente a los comicios municipales, el hecho de que sólo en seis ocasiones estos comportamientos caciquiles se planteen en una instancia provincial no hace sino demostrar el perfecto funcionamiento de los filtros* interpuestos por las compañías mineras -control de mesas electorales, Juzgados y Ayuntamientos- y el peso específico de su autoridad sobre la masa trabajadora. Si a esto añadimos que sólo en uno de los casos se emitió una resolución anuladora -en 1903, concretamente- podremos valorar las escasas perspectivas de éxito que barajaban los votantes a la hora de plantearse su desafío al poder de la empresa.

En cualquier caso, las reclamaciones electorales contra la coacción minera que llegaron a la Comisión Provincial de Huelva poseen un valor descriptivo difícilmente sustituible. Comencemos, antes que nada, por reconstruir el cuadro de las compañías encartadas entre 1898 y $1923^{37}$ :

\begin{tabular}{|c|c|c|c|c|}
\hline Reclamación & Compañia & Mina & Localidad & Dictamen \\
\hline Zalamea $14-12-1901$ & Río Tinto Company Ltd. & - & Minas de Riotinto & Válidas \\
\hline El Cerro $14-12-1901$ & Compañia de Tharsis & La Zarza & Calañas & Válidas \\
\hline P. de Guzmán 14-12-1901 & $\begin{array}{l}\text { The Bede Metal Chemical } \\
\text { - }\end{array}$ & Herrerías & $\begin{array}{l}\text { Puebla de Guzmán } \\
\text { Paymogo }\end{array}$ & $\begin{array}{l}\text { Válidas } \\
\text { Válidas }\end{array}$ \\
\hline Nerva $30-12-1903$ & '- & V: de la Peña & - & Válidas. \\
\hline El Cerro $17-12-1913$ & $\begin{array}{l}\text { Ko I into Company } \\
\text { Hijos de Vázquez López }\end{array}$ & La Joya & $\begin{array}{l}\text { Minas de Riotinto } \\
\text { El Cerro }\end{array}$ & $\begin{array}{l}\text { Nulas } \\
\text { Válidas. }\end{array}$ \\
\hline Valverde $24-3-1922$ & $\begin{array}{l}\text { S.A. Minera La Hispalense } \\
\text { S.A. de Buitrón }\end{array}$ & San Telmo & $\begin{array}{l}\text { Cortegana } \\
\text { Zalamea }\end{array}$ & $\begin{array}{l}\text { Válidas } \\
\text { Válidas }\end{array}$ \\
\hline
\end{tabular}

A la vista de estos datos, podemos enunciar ya algunas conclusiones provisionales:

(36) A.M.Z., Expedientes electorales, leg 809.

(37) La reconstrucción de lós datos se ha realizado a través de las reclamaciones electorales resueltas por la Comisión Provincial de Huelva entre 1898 y 1923 (A.D.P.H., libros 141, $143,153,160,162)$ y de PINEDO VARA, I.: Piritas de Huelva, su historia, mineria $y$ aprovechamiento. Summa, Madrid, 1963, pp. 233 y s., 262, 279 y s., 362. 
- A pesar de que, indudablemente, la Compañía de Río Tinto era la más poderosa y la que poseía un mayor poder de coacción, buena parte de las denuncias afectan a compañías mineras de pequeña o mediana entidad, que disponían de una capacidad coactiva similar, pero de una posibilidad sensiblemente menor de evitar que las reclamaciones siguiesen su curso hasta la Comisión Provincial.

- El poder de las compañías no se limita por lo general al municipio donde están enclavadas sus instalaciones, sino que sobrepasa considerablemente este marco exíguo y se extiende a los municipios del entorno donde viven sus obreros. Es más, da la impresión de que el exhaustivo control ejercido por la empresa en la localidad en la que realiza sus labores industriales impide que desde allí mismo se formulen denuncias contra ella. Observemos, en este sentido, que desde Minas de Riotinto o desde Calañas nunca se elevaron reclamaciones contra la Río Tinto Company o la Compañia de Tharsis.

- Aparentemente, no parece existir ninguna conexión entre el ejercicio de la coacción electoral y la evolución de la política provincial. Las fechas de las reclamaciones -tan irregulares- no se corresponden, ni siquiera en el caso de las referidas a la Compañía de Río Tinto, con una mayor organización de las asociaciones sindicales o un cierto fortalecimiento de las fuerzas políticas de la izquierda antidinástica; por el contrario, las oscilaciones de la presión parecen responder a las propias conveniencias coyunturales de las empresas y a la evolución del régimen municipal en las localidades de la cuenca minera.

- Aunque puede coincidir cronológicamente, la coacción no se plantea como una actuación corporativa o conjunta del grupo minero, sino que es un comportamiento particularizado de cada empresa, independientemente de las demás.

Conviene no perder de vista que las reclamaciones sólo afectan al campo de los comicios municipales. En lo que atañe a elecciones provinciales o generales carecemos de ejemplos. No obstante, no parece excesivamente desencaminado suponer que los instrumentos de presión utilizados debieron ser idénticos.

Aunque lo normal es la denuncia a secas, algunas reclamaciones contienen una riqueza de detalles que no nos resistimos a referir. La presentada en 1903 por el nervense Andrés Domínguez de León y 22 electores más indicaba

*...que a los electores que no recogían las candidaturas del empleado de la Compañía, que en la puerta del local y a la vista del Presidente las ofrecía, no se les permitía votar pretextando que ya lo habían efectuado; que no se admitieron las protestas que al finalizar la elección presentaron; ni en la certificación del escrutinio aparecían otros nombres con votos 
obtenidos, más que los que formaban la candidatura impuesta por orden circular en todos los departamentos mineros a todos los obreros....38.

La amenaza con la pérdida del empleo parece haber sido el sistema de presión habitualmente utilizado por las compañías mineras, no en valde esta pérdida solía llevar aparejada además la de la vivienda. Los capataces de la mina "La Zarza. intimidaron a los electores obreros en la misma puerta de los colegios amenazándoles con ser despedidos de sus trabajos* y los de "La Joya" se colocaron junto a la mesa "con una lista de votantes de la referida mina para tomar nota de todo el que no emitiera su sufragio a favor de la candidaturav indicada terminantemente por el Jefe de la mina a través de sus encargados ${ }^{39}$. En alguna ocasión, incluso, uno de los caciques de la comarca advirtió al candidato opositor del distrito sobre el inmenso poder del *elemento minero" que obligaba a votar amenazando con despedir hhasta a los abuelos de los que trabajaban en las minas ${ }^{40}$.

El clima de violencia y tensión que debía rodear los comicios municipales en la zona minera, especialmente en las localidades dependientes de la Compañía de Río Tinto, condujo a que los mismos obreros, en sus momentos de mejor organización, recurriesen a la presión para contrarrestar la influencia de la empresa. Entre 1898 y 1923, partieron de esta zona tres reclamaciones que denunciaban la realización de las votaciones en un ambiente de coacción obrera. Su distribución temporal -dos en 1913 y una en 1920- es de por sí bastante elocuente, ya que se corresponde con la etapa álgida del sindicalismo minero y la mayoría de edad de los socialistas y republicanos onubenses ${ }^{41}$. La pérdida de autoridad de la Rio Tinto Company en esta difícil coyuntura explica el desmoronamiento parcial de sus afiltros* institucionales y la victoria en las urnas de sus enemigos políticos.

Las tornas cambiaron en estos dos años y, sin embargo, el poder de la Compañía sobre la Comisión Provincial permaneció prácticamente ileso, pues ésta saldó dos de los pleitos a su favor declarando que el desarrollo de la huelga general y la evidencia de los hechos imponían la anulación de los comicios ${ }^{42}$.

(38) A.D.P.H., Comisión Provincial, 30-12-1903, libro 143.

(39) A.D.P.H., Comisión Provincial, 14-12-1901 y 17-12-1913, libros 141 y 153.

(40) A.P.O.R., Carta de Evaristo Martín a Ordóñ ez Rincón, El Cerro, 18-12-1889.
(41) Vid. nota 9.

(42) A.D.P.H., Comisión Provincial, 27-12-1913, libro 153. Una de estas anulaciones afectó a José Díaz del Real, primer alcalde socialista de España, electo en Nerva, aunque éste justificó su intervención en las elecciones alegando que sólo pretendía garantizar el derecho constitucional de los electores coaccionados por los capataces, encargados listeros, guardas y otros empleados de la Compañía, que les amenazaban con ser despedidos. A.D.P.H., Comisión Provincial, 29-3-1920, libro 160. 


\subsection{El control de las instituciones}

Acabamos de mencionar los "filtros" dispuestos por las compañías para evitar que las reclamaciones electorales tuviesen efecto y la perfección de su funcionamiento al conseguir que éstas llegasen a un término poco feliz en las sesiones de la Comisión Provincial. Evitar algo aparentemente tan coherente como la anulación de unas elecciones manifiestamente amañadas suponía, en la práctica, mover los hilos de un entramado caciquil en cuya órbita quedaban englobados desde los Ayuntamientos hasta los diputados provinciales, pasando por Juntas electorales, Juzgados o agentes represivos del tipo Guardia civil o Guardia municipal.

No todas las compañías, evidentemente, estaban en condiciones de granjearse tales influencias. Una vez más, ésta era también una cuestión de magnitudes. En la provincia de Huelva una retícula caciquil de esta importancia y efectividad sólo pudo ser trabada por la Río Tinto Company. El conocimiento aproximado de sus redes de poder sólo puede realizarse, por el momento, a través de sus resultados y no mediante la reconstrucción de su génesis y desarrollo, ya que la documentación de primera mano es muy escasa -cuando no inexistente- y hemos de basarnos en otras fuentes testimoniales.

Las hemerográficas son una buena base de partida, aunque deben ser tomadas con suma prudencia por tratarse en su mayoría de órganos propagandísticos de los republicanos, socialistas o sindicalistas, en general, que combaten a la Compañía sin reparar en medios. Especialmente agresivos fueron los ataques de Huelva Libre, el semanario fundado en 1916 por Eladio Fernández Egocheaga, organizador del Sindicato minero de Río Tinto, y los contenidos en los panfletos que éste emitió en 1914 para apoyar su candidatura a las Cortes ${ }^{43}$.

Con similar rotundidad se manifestaron también La Frontera y $L a$ Cría. El primero de ellos atacó varias veces el desmedido control institucional de la Compañía de Río Tinto durante su campaña en favor de la construcción de una nueva línea férrea a la que se oponía la citada empresa. Las alusiones fueron bien claras:

*...Río Tinto, con corporaciones municipales por él impuestas, con juzgados por él designados, con alcaldes a sueldo....44.

$\mathrm{Y}$ en otro lugar,

-[La Compañía tienel la creencia de que ocupando la Secretaría del Juzgado Municipal de Nerva una persona afecta, contribuiría a garantizar

(43) A este respecto, vid. PEÑA GUERRERO, M.A.: Opus cit;; GIL VARON, L.: Opus cit., p.155 y Riotinto. Papeles socioeconómicos de una mina andaluza en Régimen Colonial: catálogo de legajos antiguos de la Oficina de Registro. Universidad de Sevilla, 1984.

(44) La Frontera (Nerva), 28-3-1911. 
en todo caso el libre abuso y el atropello libre en cuantos asuntos relacionados con Río Tinto llegasen al Juzgado.45.

No obstante, los denunciantes de la Compañía fueron otros muchos. En el curso de la Restauración, y en distintas ocasiones, su monopolio institucional fue expuesto en el Congreso por Romero Robledo ${ }^{46} \mathrm{y}$ por Eduardo Barriobero.

*Allí no se mueve un alcalde, ni un juez, sin que en la balanza de la justicia ponga la vara el director de aquellas minas, Mr. Browning -denunció éste en 1914 tras sus primeros contactos con la cuenca minera-. (...) Lo que ocurre con la intervención de Mr. Browning en el Juzgado de Valverde del Camino lo sabemos perfectamente el Sr. Ministro de la Gobernación y yo. Algunos abusos, algunas cosas se han podido corregir mediante actuaciones judiciales. Sabe S.S. que se había clausurado un local del Sindicato y a los tres días se ha revocado el auto, claro está que por haberle insinuado al juez la obligación que tiene de hacer justicia (...).47.

Habría que esperar aún cuatro años para que Barriobero se convirtiese en el representante en Cortes del distrito de Valverde $y$, sin embargo, en esta sesión del 8 de noviembre de 1914, el republicano pedía ya una Comisión parlamentaria destinada a investigar las condiciones de vida en las minas de Río Tinto.

En 1918, su voz volvió a oírse de nuevo en la Cámara para denunciar la violencia desplegada contra los obreros durante la huelga general de agosto de 1917. Eludió entonces Barriobero el tema de la manipulación de los Juzgados y centró su interés en la forma en que la Compañía ejercía su autoridad sobre la propia Guardia civil:

-Aquellas compañías, principalmente la de Río Tinto, se cuidan de tener a su devoción constantemente a la Guardia civil, acaso no con sobornos, acaso no con gratificaciones de momento (creo yo que su reglamento prohíbe tomarlas y necesitaría yo verlo para poder decir que toman esas gratificaciones); pero sí con promesas de que, cuando cesen en el Instituto de la Guardia civil, hacerles guardiñas como los hacen en las minas de Río Tinto y los tienen allí con un sobresueldo compatible con su retiro toda la vida y por eso hacen allí lo que las compañías quieren que hagan, ${ }^{48}$.

Fuera de las Cámaras, también pudo percibirse el eco de estas denuncias. En su relato novelado sobre la vida en la cuenca minera, Concha Espina aludió a la multitud de organismos que controlaba la

(45) La Frontera (Nerva), 3-7-1911. También puede verse La Cría (Huelva), noviembre 1916.

(46) Diario de Sesiones del Congreso, 17-2-1888.

(47) Diario de Sesiones del Congreso, 3-11-1914

(48) Diario de Sesiones del Congreso, 1-6-1918. 
Compañía y "que acudirían a servirles en cuanto fuera menester ${ }^{49}$. Más tarde, el mismo Egocheaga, con su característico estilo punzante, volvió a retomar la denuncia en el prólogo que escribió para la autobiografía del sindicalista onubense Félix Lunar ${ }^{50}$.

$\mathrm{Si}$ los testimonios expuestos, en su conjunto, ofrecen suficientes visos de verosimilitud hemos de reconocer que la Compañía de Río Tinto se configuró, en efecto, como una potencia caciquil de primer orden. Arbitró a su sombra un perfecto sistema de control sobre el aparato judicial de la comarca que comenzaba, presumiblemente, con la intervención en el nombramiento de los jueces municipales y que terminaba influyendo en éstos para que dictaminasen a su favor en los asuntos pendientes de resolución que interesaban a la Compañía. Básicamente, éstos parecen haber sido dos: el control de las asociaciones sindicales (cierre de casinos obreros, sindicatos u otros centros de carácter político o societario) y la supervisión de los procesos electorales. De hecho, no es extraño que algunas reclamaciones electorales donde se denuncian coacciones de las Compañías estén aparejadas a denuncias sobre la actuación indiscriminada de los jueces durante los comicios.

Similares objetivos incitarían también a mantener el control sobre las fuerzas represivas oficiales. Elemento imprescindible para evitar alteraciones del orden público en las minas, disturbios contra la Compañía y, en general, para prevenir mediante el amedrentamiento huelgas, paros o agitaciones revolucionarias, los diferentes cuerpos policiales al servicio de la Compañía fueron utilizados con frecuencia como elementos coactivos durante los períodos electorales. Así, las municipales de 1903 o 1920, por ejemplo, se realizaron bajo un verdadero estado de ocupación arma$\mathrm{da}$, que intimidaba a los electores y decantaba su voto a favor de las candidaturas propuestas por la dirección.

En el estricto terreno de la intervención política, la Río Tinto Company debió tener, además, bajo su mandato a las Juntas Municipales del Censo Electoral, que realizaban, como demuestran las reclamaciones registradas, un primer efiltrado: de los candidatos que aspiraban a competir en las urnas y a través de las cuales se manipulaba la elaboración del censo y la composición de las mesas electorales -segundo "filtro" no ya de candidatos, sino de votos y votantes-. En última instancia, para las reclamaciones que llegasen a la Comisión Provincial -pidiendo anulación de elecciones o incapacitación de concejales- convenía tener garantizado un respaldo tácito por parte de los diputados provinciales que depurase, como efectivamente se hizo, el resultado final de sus acuerdos.

(49) ESPINA, C.: El metal de los muertos (1920). Madrid, 1941, p. 326.

(50) LUNAR, F.: Opus cit., p. 111. 


\section{CONCLUSIONES}

Concluir estas páginas sin aportar algunas reflexiones finales sobre el funcionamiento político de las empresas mineras de la provincia de Huelva nos parece desatender una imperiosa deuda contraída desde el momento en que decidimos titular este trabajo como . Caciquismo y poder empresarial.

No vamos a insistir de nuevo en algo que ya hemos expuesto con antelación y que se reduce a ver en el comportamiento caciquil de las compañías mineras un ejemplo prototípico de la utilización del poder político por parte de un poder económico que busca salvaguardar sus intereses. Aclararemos mejor que esta situación de facto, que en el contexto de la vida política nacional no reviste ninguna excepcionalidad, constituye una forma peculiar de funcionamiento en lo que se refiere a la Huelva de la Restauración. En la provincia onubense, las relaciones entre el poder económico y el poder político presentan, por lo general, otro planteamiento. Normalmente, ambos poderes coexisten, se confunden y simultanean encarnados por las mismas personas. El cacique viticultor del Condado o el empresario naviero o pesquero de la zona costera occidental es, a la vez, gestor económico de su empresa y alcalde, diputado o jefe de partido. El caso de las compañias mineras nos ofrece, en este sentido, una forma de comportamiento peculiar, ya que estas entidades impersonales, compuestas por un número variable de accionistas, no ejercen el poder político de una forma directa ni aspiran a ejercerlo, pero lo utilizan desde fuera e influyen en él decisivamente, esgrimiendo muy diferentes instrumentos de presión.

En uno y otro caso, los poderes económicos -desde fuera o desde dentro- se comportan como verdaderos gestores políticos. Estriba la diferencia, no obstante, en que la desvinculación "oficial" de las compañías mineras respecto a la política las convierte en un auténtico grupo de presión a la manera de los descritos por Tuñón de Lara en Historia y realidad del poder.

Ahora bien, este carácter de grupo de presión no debe ocultarnos una realidad incuestionable: las sociedades mineras onubenses no actuaron nunca como verdaderos núcleos corporativos o como asociaciones patronales constituidas en pro de la defensa de unos intereses comunes. Su acción en la provincia de Huelva se realizó siempre con una notable independencia, sin que llegaran nunca a establecerse las pautas de una actuación conjunta. El único intento reseñable de integración minera culminó con la constitución de la Asociación de Mineros Exportadores, si bien la no participación de la Río Tinto Company y de la Compañía de Tharsislas dos entidades empresariales más potentes de la minería provincial- 
redujo drásticamente su poder fáctico y sus posibilidades de intervenir con efectividad en la política. Las abismales diferencias de magnitud entre las empresas, entre una Compañía de Río Tinto fuertemente capitalizada y conectada con los mercados internacionales y las pequeñas empresas integradas por apenas dos o tres concesiones mineras, podrían explicar parcialmente que, en la práctica, no se compartieran unos intereses aparentemente comunes. Por lo demás, el hecho de que entre las empresas existiesen tan profundas diferencias de nacionalidad y de que las explotaciones se plantearan en un sentido colonial pudo contribuir también, de forma esencial, al mantenimiento de su aislamiento corporativo.

En cualquier caso, lo que parecen definir estas líneas no es sino la gran versatilidad y flexibilidad del sistema caciquil de la Restauración española, capaz de absorber e integrar los intereses de los distintos poderes sociales y de ser ejercido no sólo por aquellos caciques que lo sostuvieron y para los que fue diseñado, sino incluso por empresas extranjeras ajenas por naturaleza, como ha escrito David Avery, al slaberinto de la política española. 